\title{
PERANCANGAN MEDIA INTERPRETASI WISATA BUDAYA \\ DALAM RANGKA MENINGKATKAN MOTIVASI \\ PENGALAMAN BERKUNJUNG WISATAWAN DI DAYA \\ TARIK GALERI 16-INDONESIAN BAMBOO SOCIETY
}

\author{
Nurul Rochmah Pramadika ${ }^{1}$ \\ Prodi Magister Pariwisata Berkelanjutan \\ UNIVERSITAS PADJADJARAN \\ Nurul19004@mail.unpad.ac.id \\ Rusdin Tahir ${ }^{2}$ \\ Prodi Magister Pariwisata Berkelanjutan \\ UNIVERSITAS PADJADJARAN \\ rusdin@unpad.ac.id \\ Cecep Ucu Rakhman ${ }^{3}$ \\ Prodi Magister Pariwisata Berkelanjutan \\ UNIVERSITAS PADJADJARAN \\ Cecep.u.r@gmail.com \\ Awaludin Nugraha ${ }^{4}$ \\ Prodi Magister Pariwisata Berkelanjutan \\ UNIVERSITAS PADJADJARAN \\ Awaludin.nugraha@unpad.ac.id \\ Tommy Andrianto 5 \\ Prodi Usaha Perjalanan Wisata \\ POLITEKNIK NEGERI BANDUNG \\ Tomyandrianto@polban.ac.id
}

\begin{abstract}
This research aims to build a model of interpretation media design as an effort to improve the motivation of experience visiting tourists with the appeal of cultural tourism. The design of interpretation media in this research, including; Interpretation board design, interpretation path design in three-dimensional (3D) form, slide show design in the gallery entrance area. The interesting phenomenon in the presentation of a collection of displays that do not have the medium of interpretation as an information provider of a cultural tourism attraction. The results of documentary studies and interviews with visitors concluded that the experience of visiting Galeri 16 - Indonesian Bamboo Society had difficulty understanding information from each collection of displays, according to the context which in fact
\end{abstract}


museums such as Galeri 16 - Indonesian Bamboo Society must be able to provide an interpretation of the function or meaning of collection objects. Based on phenomenon the author feels that it is necessary to design several media interpretations as a facility for tourists in order to improve the tourist experience when traveling in the Galeri 16-IBS.

Keywords : Tourist Attraction, Motivation, Experience, Design, Interpretation media

\begin{abstract}
ABSTRAK
Riset ini bertujuan membangun model perancangan media interpretasi sebagai upaya meningkatkan motivasi pengalaman berkunjung wisatawan dengan daya tarik wisata budaya. Rancangan media interpretasi dalam penelitian ini, diantaranya adalah; Rancangan papan interpretasi, rancangan jalur interpretasi dalam bentuk tiga dimensi (3D), rancangan slide show di area masuk galeri. Fenomena menarik dalam penyajian koleksi pajangan yang belum memiliki media interpretasi sebagai pemberi informasi dari sebuah atraksi wisata budaya. Hasil studi dokumentsi dan wawancara terhadap pengunjung memberikan kesimpulan bahwa pengalaman saat berkunjung ke Galeri 16 - Indonesian Bamboo Society kesulitan dalam memahami informasi dari setiap koleksi pajangan, yang sejatinya museum seperti Galeri 16 Indonesian Bamboo Society harus mampu memberikan interpretasi fungsi ataupun makna benda-benda koleksi sesuai dengan konteks. Melihat fenomena yang ada penulis merasa perlu dirancang beberapa media interpretasi sebagai fasilitas bagi wisatawan dalam rangka meningkatkan pengalaman ketika berwisata budaya di Galeri 16-IBS.
\end{abstract}

Kata kunci: Daya Tarik, Motivasi, Pengalaman berkunjung, Rancangan, Media interpretasi

\title{
PENDAHULUAN
}

Pariwisata adalah suatu industri yang terintegrasi satu sama lain dimana seluruh komponen di dalamnya saling mendukung memenuhi kebutuhan wisatawan. Berdasarkan Undang - undang tentang kepariwisataan, Pariwisata yang terdiri dari berbagai macam kegiatan wisata, sebaiknya didukung berbagai fasilitas serta layanan yang disediakan oleh masyarakat, pengusaha, pemerintah, dan Pemerintah Daerah (pasal 1, ayat 3, UU RI No.10 Tahun 2009).

Industri pariwisata menjadi perhatian bagi banyak Negara di dunia salah satunya karena mampu menyumbang devisa negara yang besar. Pendekatan pariwisata akan menunjang peningkatan ekonomi dengan memanfaatkan seluruh potensi yang dimiliki sebuah kawasan. Tidak hanya itu, pariwisata memberikan andil terhadap terbukanya lapangan pekerjaan baru bagi suatu daerah yang memiliki potensi pariwisata. Saat ini wisata budaya menjadi hal yang menarik sesuai dengan hasil penelitian yang telah dilakukan oleh (PulidoFernández, Carrillo-Hidalgo, \& Mudarra-Fernández, 2019), "In recent years, scientific literature has shown special interest in the identification of the factors 
-

that influence tourism expenditure, especially in cultural destinations. However, very few studies of this type have been undertaken in World Heritage Cities."

Menurut data The Travel and Tourism Competitiveness Index yang dilansir World Economic Forum (WEF, 2013), Indonesia merupakan negara yang menonjol pada kategori budaya, warisan sejarah termasuk kekayaan dan keindahan alamnya. Indonesia juga banyak diminati oleh wisatawan yang menyukai atraksi wisata budaya. Salah satu daya tarik wisata budaya yang dapat dikunjungi di Kota Bandung adalah Galeri 16-IBS. Di tengah hiruk pikuk keramaian kendaraan bermotor dalam kota, sebuah bangunan yang menyimpan aset budaya, berada tepat di pinggir Jalan Raya Cibeureum. Dari luar, bangunan ini tampak sederhana dan banyak yang tidak mengetahui apa saja yang tersimpan di dalamnya. Saat penulis melakukan survei ke dalam tempat ini, banyak bendabenda unik yang terbuat dari bambu tepajang di dalamnya. Bangunan ini diberi nama Galeri 16-IBS (Indonesia Bamboo Society). Beberapa pajangan di galeri ini belum memiliki interpretasi dimana pengunjung tidak dapat mengetahui informasi dari setiap karya seni yang terpajang dalam galeri ini, kecuali pengunjung bertanya langsung kepada pemilik galeri ini. Berdasarkan wawancara dengan Drs. Taufiq Rukman selaku Ketua Umum Indonesia Bamboo Society, Galeri 16-IBS merupakan sebuah museum dimana tempat ini adalah lembaga non-profit. Pengutaraan Drs. Taufiq Rukman sesuai dengan Ardika (2012) yang mengatakan bahwa museum adalah tempat memamerkan atau memajang benda warisan budaya yang menjadi daya tarik wisata, di sisi lain industri pariwisata mendapat keuntungan ekeonomi sehingga dapat membantu keberadaan museum sebagai lembaga nirlaba (non profit). Ketua Umum Galeri-16 IBS menambahkan mengenai atraksi wisata, Atraksi wisata yang utama di galeri ini adalah kriya bambu dan seni lukis.

Jumlah pajangan yang ada di Galeri 16-IBS ada sekitar 800 buah. Permasalahannya adalah tidak ada Sumber Daya Manusia yang ditunjuk khusus sebagai guide untuk melayani pengunjung. Seluruh informasi hanya dapat kita gali dari narasumber sekaligus pemilik Galeri 16-IBS secara langsung yaitu, Ny. Tien Anang Sumarna, isteri dari Drs. Anang Soemarna (Alm) selaku pendiri Galeri 16-IBS. Hal lain dari itu, hasil wawancara dengan salah satu wisatawan yang berkunjung ke Galeri 16-IBS, penulis mendapatkan gambaran bahwa pengunjung mengharapkan adanya media yang dapat memberikan informasi di Galeri 16-IBS untuk membantu pengunjung memahami isi dari apa yang dipamerkan di Galeri-IBS. Maka dari itu, penulis ingin merancang beberapa media interpretasi tak langsung yang dapat membantu pengunjung dalam mendapatkan informasi dari karya seni yang terpajang di Galeri 16-IBS, sekaligus meningkatkan pengalaman kepada wisatawan yang berkunjung.

Menurut Yoeti (2006) di Indonesia, Pengembangan pariwisata menggunakan konsepsi budaya telah dirumuskan dalam Undang-undang. Undang-undang yang berisi mengenai hal tersebut adalah Undang-undang Pariwisata Nomor 09 Tahun 1994, "Pariwisata Budaya merupakan salah satu jenis Kepariwisataan yang dikembangkan bertumpu pada kebudayaan. Kebudayaan yang dimaksud adalah kebudayaan Indonesia yang berdasarkan Pancasila."

Kesrul (2003) menyebutkan bahwa wisata budaya merupakan salah satu dari daya tarik wisata yang memberikan pengetahuan mengenai kebudayaan suatu 
tempat, baik dilihat dari segi suku, adat istiadat maupun lainnya. Pengertian wisata budaya dari McKercher dan du Cros (dalam Buhalis dan Costa, 2006, hal. 211), "Cultural tourism is a form of tourism that relies on a destination's cultural heritage assets and transforms them into products that can be consumed by tourists". Dapat ditarik kesimpulan bahwa wisata budaya adalah wisata yang mengandalkan aset warisan budaya dengan tujuan menjadikan produknya dapat dinikmati oleh wisatawan.

Salah satu komponen kepariwisataan adalah atraksi wisata. (Cooper dkk, 2011) menyebutkan bahwa Atraksi Wisata adalah salah satu dari komponen kepariwisataan, dan memiliki pengertian yaitu, suatu objek yang memiliki daya tarik bagi seseorang untuk menikmati atau menyaksikan objek tersebut. Secara umum ada tiga jenis atraksi wisata yakni:

a. Atraksi alam (natural attraction)

b. Atraksi budaya (cultural attraction) atau man-made dan,

c. Atraksi minat khusus (special attraction).

Pengertian lain dari (Gunn, 2011) mengenai Atraksi Wisata yaitu, daya tarik utama bagi individu untuk melakukan pejalanan, atraksi memiliki dua fungsi yaitu sebagai daya pikat, perangsang individu untuk melakukan perjalanan dan sebagai pemberi kepuasaan bagi pengunjung.

Dari pengertian di atas, dapat disimpulkan bahwa Atraksi Wisata adalah sebuah objek di kawasan wisata yang memunculkan daya tarik bagi wisatawan untuk mengunjunginya. Dan menurut Kamus Besar Bahasa Indonesia (KBBI), pengertian Atraksi Wisata Budaya adalah seni, budaya, warisan sejarah, tradisi, kekayaan alam, atau hiburan, yg merupakan daya tarik wisatawan di daerah tujuan wisata. Berdasarkan uraian tersebut, Atraksi Wisata Budaya dapat didefinisikan sebagai objek yang berkaitan dengan kebudayaan yang dapat memunculkan daya tarik kepada wisatawan di daerah tujuan wisata.

Tilden dan Wallin (2008) mengatakan pengertian Interpretasi adalah Suatu kegiatan pendidikan yang ditujukan untuk mengungkapkan arti dan hubungan melalui penggunaan objek asli, dengan pengalaman pertama, dan dengan media yang bersifat ilustratif, bukan hanya sekedar mengkomunikasikan informasi. Serta membantu pengunjung merasakan hal yang dirasakan oleh interpreter - kepekaan terhadap keindahan, kompleksitas, keragaman dan saling keterkaitan dalam lingkungan; rasa kagum; hasrat untuk mengetahui. Interpretasi harus membantu pengunjung mengembangkan perasaan bahwa lingkungan adalah rumah mereka. Interpretasi harus membantu pengunjung mengembangkan persepsi.

Rachmawati (2008) menyimpulkan bahwa interpretasi merupakan suatu seni dalam menjelaskan keadaan lingkungan oleh pengelola kawasan kepada pegunjung yang datang ke lingkungan tersebut sehingga dapat memberikan inovasi dan menggugah pemikiran untuk mengetahui, menyadari, mendidik dan bila memungkinkan menarik minat pengunjung untuk ikut menjaga lingkungan tersebut ataupun mempelajarinya lebih lanjut. Dan media interpretasi adalah suatu bahan atau alat untuk berkomunikasi dengan pengunjung dalam rangka penyelenggaraan interpretasi.

Berdasarkan Buhalis dan Costa (2006) bahwa Interpretasi adalah salah satu yang akan berpengaruh terhadap pengembangan warisan budaya dan atraksi. Interpretasi dalam pengembangan atraksi wisata culture and heritage dijelaskan (McKercher dan du Cros, 2006), "The presentation of culture for tourist 
consumption will also face additional challenges". Menurut Marpaung dan Barah (2002), peranan interpretasi dalam warisan budaya mendorong pengalaman dan merupakan bagian terpenting dari program pengembangan pariwisata yang baik. Definisi interpretasi oleh Tilden (1977) dalam (buku) "Interprenting Our Culture" (dalam Marpaung dan Barah, 2002, hal. 42) Interpretasi adalah suatu kegiatan yang bertujuan mengungkap makna dan hubungan lewat penggunaan obyek asli, melalui pengalaman langsung. Kastolani dkk (2016) menambahkan bahwa model desain interpretasi akan berdampak pada perubahan sikap pengunjung terhadap pengalaman lebih positif.

Setiap individu memiliki motivasi tersendiri dalam menentukan pilihan tempat yang ingin dikunjunginya, didukung oleh kutipan dari (Tercia, et.al, 2020) "Potential travelers need to anticipate their vacation experiences when making their travel destination choices". Sebuah penelitian telah dilakukan oleh Diaz, et.al (2016) di Pulau Santay yang berada di Ecuador. Hasil dari penelitian tersebut menyatakan bahwa dimensi motivasi berengaruh terhadap keputusan wisatawan saat mengunjungi tempat wisata.

(McIntosh, 1977) mengungkapkan bahwa pada dasarnya seseorang melakukan perjalanan dimotivasi oleh beberapa hal. Dari berbagai motivasi yang mendorong perjalanan, motivasi-motivasi tersebut dapat dikelompokan menjadi empat kelompok besar sebagai berikut:

1. Physical or physiological motivation (motivasi yang bersifat fisik atau fisiologis), antara lain untuk relaksasi, kesehatan, kenyamanan, berpartisipasi dalam kegiatan olah raga, bersantai, dan sebagainya.

2. Cultural motivation (motivasi budaya), yaitu keinginan untuk mengetahui budaya, adat, tradisi, dan kesenian daerah lain. Termasuk juga ketertarikan akan berbagai objek tinggalan budaya (monumen bersejarah).

3. Social motivation atau interpersonal motivation (motivasi yang bersifat sosial), seperti mengunjungi teman dan keluarga (VFR/Visiting friends and relatives), menemui mitra kerja, melakukan hal-hal yang dianggap mendatangkan gengsi (nilai prestise), pelarian dari situasi-situasi yang membosankan, dan seterusnya.

4. Fantasy motivation (motivasi karena fantasi), yaitu adanya fantasi bahwa di daerah lain seseorang akan bisa lepas dari rutinitas keseharian yang menjemukan dan ego-enhancement yang memberikan kepuasan psikologis atau biasa disebut sebagai status and prestige motivation.

Muksin dan Sunarti (2018) menjelaskan Motivasi merupakan faktor penting bagi calon wisatawan di dalam mengambil keputusan mengenai daerah tujuan wisata yang akan dikunjungi. Penelitian yang telah dilakukan oleh (Lopez-Guzman, Pérez Gálvez, Muñoz-Fernández, \& Medina-Viruel, 2018) menyebutkan bahwa budaya merupakan salah satu dari dimensi motivasi mengapa seseorang ingin mengunjungi sebuah kota, "The results demonstrate the existence of three motivational dimensions among foreign visitors to visit the city: firstly cultural, secondly circumstantial and finally hedonic-gastronomic"

\section{METODOLOGI}

Metode yang digunakan dalam penelitian ini adalah metode penelitian kualitatif deskriptif. Menurut Sugiama (2008, hal.31) Penelitian kualitatif adalah 
prosedur suatu penelitian yang mengumpulkan data berupa kata-kata tertulis atau lisan dari orang-orang dan perilaku yang dapat diamati secara deskriptif. Sedangkan pandangan Miles dan Huberman (Iskandar dkk, 2010) terhadap penelitian kualitatif adalah data yang muncul berwujud kata-kata dan bukan rangkaian angka. Menurut Rahardjo (2011), salah satu teknik pengumpulan data dalam penelitian kualitatif adalah melalui wawancara. Wawancara merupakan proses komunikasi atau interaksi untuk mengumpulkan informasi dengan cara tanya jawab antara peneliti dengan informan.

Data diperoleh dari informasi pihak pengelola Galeri 16-IBS dan melakukan studi pustaka. Adapun teknik pengumpulan data dilakukan dengan melakukan observasi dan wawancara dengan stakeholder, pihak pengelola, dan pengunjung galeri. Metode analisis data yang digunakan adalah metode analisis deskriptif. Berdasarkan hasil analisis data inilah dapat terungkap bagaimana potensi pengembangan yang dapat dilakukan di Galeri 16-IBS. Selanjutnya, dari hasil analisis data ini akan disusun bagaimana perancangan interpretasi yang dapat diterapkan di Galeri 16-IBS.

\section{HASIL DAN PEMBAHASAN}

\section{A. Gambaran Perancangan Papan Interpretasi di Galeri 16-IBS}

Menurut Ardiyani dkk (2013) salah satu cetakan dua dimensi dalam ragam media interpretasi adal papan interpretasi. Penulis memiliki rancangan papan interpretasi untuk memberikan informasi secara tidak langsung kepada wisatawan yang berkunjung ke Galeri 16-IBS. Papan interpretasi berperan sebagai interpreter yang dapat menerangkan informasi dan memberikan pesan kepada wisatawan yang berkunjung tanpa perlu dipandu oleh guide. Berikut adalah salah satu rancangan papan interpretasi yang dapat diaplikasikan dengan koleksi pajangan di Galeri 16IBS.

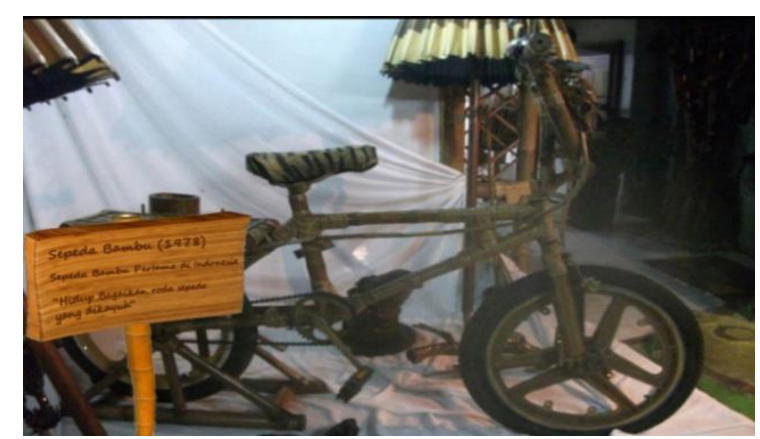

\section{Gambar 1. Sepeda bambu dengan rancangan papan interpretasi} (Sumber: Dokumentasi penulis, 2014)

Ketika sebuah pajangan hanya tersimpan tanpa informasi apapun, wisatawan tidak akan mendapatkan wawasan mengenai benda tersebut. Interpretasi dari pajangan sepeda ini memberikan informasi kapan sepeda tersebut dibuat, kemudian ada kata-kata mutiara yang dapat menambah kesan kepada pengunjung yang membaca papan interpretasi tersebut. Monika dkk (2018) menyimpulkan dari hasil penelitiannya bahwa papan interpretasi sebagai media interpretasi nonpersonal dapat memberikan pengetahuan dan edukasi bagi wisatawan. Dari gambar tersebut dapat terlihat rancangan papan interpretasi yang penulis aplikasikan pada 
koleksi di Galeri 16-IBS. Sebelumnya koleksi sepeda bambu ini tidak memiliki media interpretasi. Wisatawan yang mengunjungi tidak dapat mengetahui informasi dari koleksi tersebut, minimal nama koleksi dan tahun pembuatannya. Jika sudah diberi papan interpretasi seperti gambar di atas akan sangat memudahkan wisatawan untuk mendapatkan wawasan yang tentunya meningkatkan pengalaman berkunjung di Galeri 16-IBS.

\section{B. Gambaran Perancangan Jalur Interpretasi di Galeri 16-IBS}

Menurut Sugiarta dkk (2013) tujuan dari perencanaan jalur interpretasi adalah agar wisatawan mendapatkan pesan (message) berupa pengalaman dan pemahaman. Dari penjelasan tersebut, penulis merancang sebuah jalur interpretasi di Galeri 16-IBS sebagai media untuk membantu wisatawan dalam melakukan tur wisata budaya tanpa dipandu oleh guide, dan jalur interpretasi dibuat dalam bentuk tiga dimensi untuk memberikan pengalaman tersendiri bagi wisatawan yang berkunjung ke Galeri 16-IBS. Jalur Interpretasi (interpretation trial) disajikan dalam bentuk tiga dimensi agar lebih memberikan kesan menarik terhadap wisatawan yang berkunjung. Selain itu, media interpretasi tiga dimensi ini dilengkapi oleh audio yang memandu pengunjung untuk tour di Galeri 16-IBS. Menurut Vaughan (2004) audio adalah elemen multimedia yang paling memiliki sensansi. Audio dalam produk multimedia bisa disajikan baik dalam bentuk musik, efek suara, atau narasi yang dapat menciptakan suasana suatu produk multimedia lebih hidup.

Berikut adalah alur dari jalur interpretasi (interpretation trial) wisata budaya di Galeri 16-IBS;

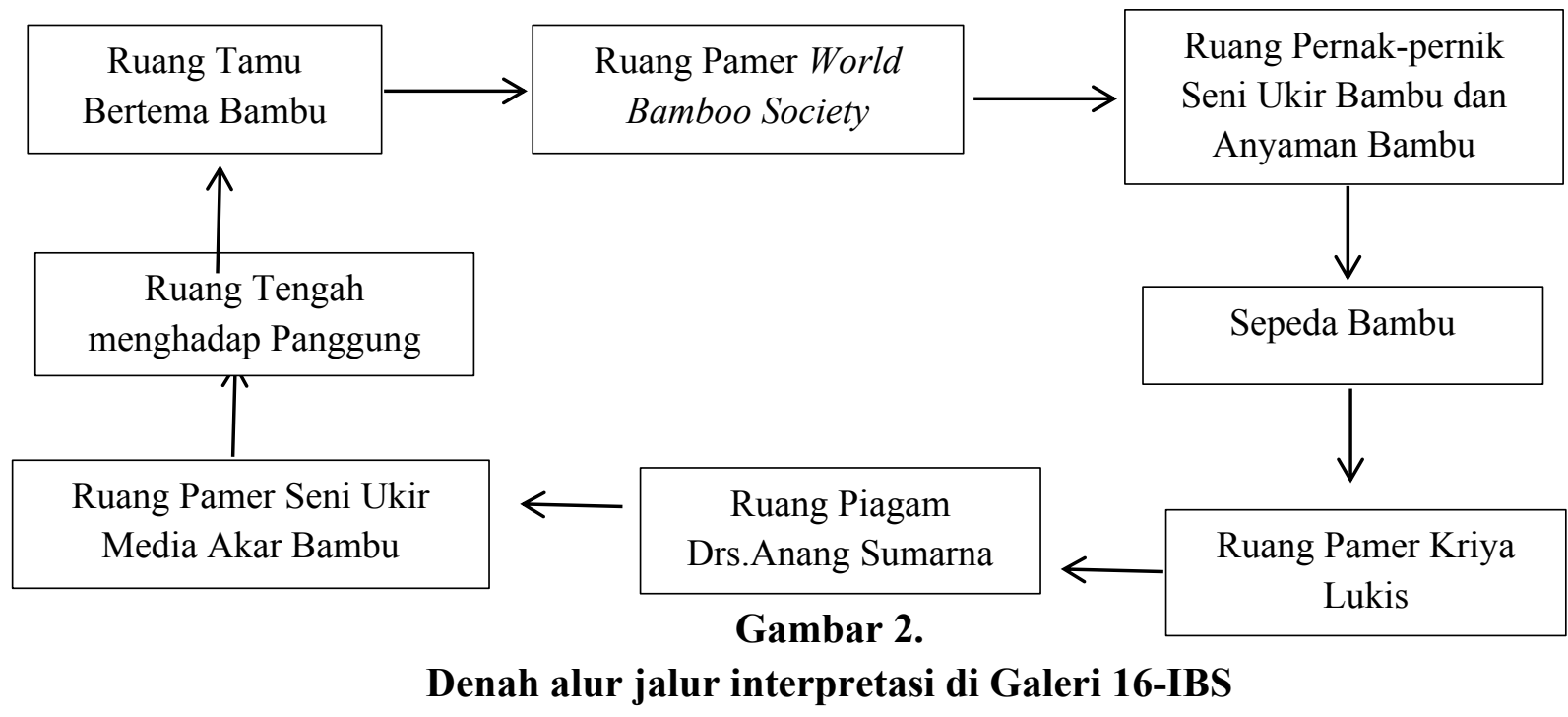


Denah yang dirancang untuk menggambarkan alur jalur interpretasi yang memudahkan wisatawan ketika berkunjung di Galeri agar menikmati pajangan secara keseluruhan karena Najib (2019) berpendapat bahwa wisatawan mengharapkan dapat memperoleh pengetahuan yang mendalam setelah melakukan kegiatan wisata. Hal tersebut dapat diwujudkan melalui kegiatan interpretasi jalur wisata.

\section{Gambaran Perancangan Video Slide Galeri 16-IBS}

Proyek rancangan video slide yang berisikan gambaran umum dari sebuah atraksi wisata budaya sebagai media interpretasi yang dapat disaksikan oleh wisatawan untuk mendapatkan informasi mengenai sejarah, prestasi, kegiatan, dan koleksi pajangan di Galeri 16-1BS. Video slide merupakan salah satu media interpretasi audio visual sesuai dengan pendapat Syaputra dkk (2019) sarana interpretasi kepariwisataan adalah semua fasilitas informasi yang memungkinkan agar aktivitas kepariwisataan dapat hidup dan berkembang serta dapat memberikan pelayanan pada wisatawan untuk memenuhi kebutuhan informasi yang beraneka ragam. Sarana interpretasi wisata juga dapat diartikan sebagai bagian kelengkapan daerah tujuan wisata yang diperlukan untuk melayani kebutuhan informasi wisatawan dalam menikmati perjalanan wisatanya.

Di zaman era digital seperti saat ini media berbasis teknologi menjadi modal untuk memfasilitasi berbagai kegiatan sehari-hari, salah satunya dalam berwisata. Media video slide yang dirancang oleh penulis diharapkan membantu memberikan informasi kepada wisatawan dan menambah kesan menarik ketika berkunjung ke Galeri 16-IBS, seperti dikatakan Daye (2005),"The media is a primary source of destination images". Melalui media interpretasi dalam video slide yang dirancang dalam proyek ini, wisatawan dapat mengetahui gambaran atraksi wisata budaya di Galeri 16-IBS

\section{SIMPULAN}

Berdasarkan dari hasil uraian-uraian penulis sebelumnya, dapat ditarik kesimpulan bahwa motivasi merupakan faktor penting bagi seseorang untuk mengunjungi sebuah daya tarik wisata. Pengalaman berkunjung yang bermakna menjadi salah satu kebutuhan dalam menambah nilai pada pengelolaan daya tarik wisata. Informasi non-verbal berupa media interpretasi menjadi salah satu upaya untuk menambah nilai kunjungan. Pada saat observasi dilaksanakan, Galeri 16Indonesian bamboo society belum memiliki media informasi yang bermakna dalam menginterpretasi koleksi pajangannya. Wisatawan yang mengunjungi galeri tersebut memiliki motivasi budaya, namun informasi yang didapatkan sangat minim karena kurangnya media yang membantu mereka selama berada disana. Tujuan dari media interpretasi disini memudahkan pengunjung dalam memahami makna tambahan pada koleksi pajangan. Rancangan dibuat berdasarkan kebutuhan pengunjung dan diskusi dengan pengelola sebagai fasilitas tambahan dalam meningkatkan pengalaman berkunjung pada daya wisata budaya. Fungsi dan makna setiap panjangan bisa berbeda dalam interpretasi masing-masing orang. Hasilnya, terdapat tiga rancangan yang ditawarkan, yaitu pertama rancangan papan informasi setiap koleksi pajangan, kedua yaitu informasi mengenai jalur kujungan yang 
berbentuk 3 dimensi dan yang ketiga adalah rancangan slides show yang ditempatkan di area depan galeri. Ketiga rancangan ini meyesuaikan konteks pajangan dengan kebutuhan pengunjung. Tantangan selanjutnya mengimplementasikan rancangan dari segi biaya dan pemanfaatanya untuk pengunjung. Rancangan media interpretasi ini tidak hanya dapat diaplikasikan di Galeri 16-IBS, namun daya tarik wisata lainnya pun dapat mengimplementasikan model dari rancangan media interpretasi wisata ini. Penelitian yang akan dilakukan selanjutnya dengan model sejenis dapat diperbaharui karena sektor pariwisata bergerak dinamis ditunjang oleh teknologi yang terus berkembang.

\section{DAFTAR PUSTAKA}

Ardika, I.Wayan. (2012). Museum sebagai Daya Tarik Wisata. Diakses pada: http://iaaipusat.wordpress.com/tag/i-wayan-ardika/

Buhalis, Dimitros dan Costa, Carlos. (2006). Tourism Business Frontiers. Oxford: ELSEVIER

Crouch, David., Jackson, Rhona, dan Thompson, Felix. (2005). The Media and The Tourist Immagination converging cultures. New York: Routledge

Diaz-Christiansen S., López-Guzmán T., Pérez Gálvez J.C., Muñoz Fernández G.A. (2016). Wetland tourism in natural protected areas: Santay Island (Ecuador). Elsevier : 10.1016/j.tmp.2016.07.005

Kastolani, Wanjat., Fitri, Rahmafitria., Diceu, Hanna.P. (2016). Pengaruh Interpretasi Terhadap Kepuasan Wisatawan Berkunjung di Museum Nasional Gedung Perundingan Linggarjati Kabupaten Kuningan. Jurnal Manajemen Resort dan Leisure Vol.13, No.1, April.

Kesrul, M. (2003). Penyelenggaraan Operasi Perjalanan Wisata. Jakarta: PT Gramedia Pustaka Utama

Lopez-Guzman, T., Pérez Gálvez, J. C., Muñoz-Fernández, G. A., \& MedinaViruel, M. J. (2018). Cultural identity in WHS tourist destinations: the case of Cordoba (Spain). International Journal of Culture, Tourism, and Hospitality Research, 12(4), 427-439. https://doi.org/10.1108/IJCTHR-05-2018-0065

McIntosh. (1977). Karakteristik Wisatawan. Yogyakarta: ANDI.

Pulido-Fernández, J. I., Carrillo-Hidalgo, I., \& Mudarra-Fernández, A. B. (2019). Factors that influence tourism expenditure in World Heritage Cities. Anatolia, 30(4), 530-546. https://doi.org/10.1080/13032917.2019.1650083

Marpaung, Happy dan Barah, Herman. (2002). Pengantar Pariwisata. Bandung: Alfabeta

Monika, Lela., Fitri, Rahmafitria., Upi, Supriatna. (2018). Perencanaan Media Interpretasi Non-Personal Sejarah di Wana Wisata Kawah Putih Kabupaten Bandung. Jurnal Pendidikan Ilmu Sosial Volume 27, Nomor 1, Juni. 
Muksin, D. R. M., \& Sunarti. (2018). Pengaruh Motivasi terhadap Keputusan Berkunjung Wisatawan di Ekowisata Mangrove Wonorejo Surabaya. Jurnal Administrasi Bisnis (JAB)|Vol.55, 55(1), 196-203. Retrieved from http://administrasibisnis.studentjournal.ub.ac.id/index.php/jab/article/view/22 58

Najib, Nardy.N. (2019). Perencanaan Interpretasi Wisata Di Resort Minasa Te'ne, Taman Nasional Bantimurung Bulusaraung. Jurnal Penelitian Kehutanan Bonita. Volume 1 Nomor 1 Juli

Rachmawati, Eva. (2008). Interpretasi. Diakses pada:

http://vwa.staff.ipb.ac.id/files/2011/02/Interpretasi-JICA.doc

Sugiama, A.Gima. (2011). Pengantar Bisnis Pariwisata. Bandung: PT Guardaya Intimarta

Sugiama, A.Gima. (2008). Metode Riset Bisnis dan Manajemen. Bandung: PT Guardaya Intimarta

Syaputra, Maiser., Lesmono.A,I Mahakam, dan Indriyanto. (2019). Penataan Kawasan Embung Aik Bual melalui Penguatan Media Interpretasi Wisata. Volume 1, Nomor 1.

Tercia, C., Teichert, T., Sirad, D., \& Soehadi, A. (2020). Conveying pre-visit experiences through travel advertisements and their effects on destination decisions. Journal of Destination Marketing and Management, 16(April), 100331. https://doi.org/10.1016/j.jdmm.2018.12.005

Undang-Undang Republik Indonesia Nomor 10 Tahun 2009 tentag Kepariwisataan Yoeti, Oka.A. (2006). Pariwisata Budaya. Jakarta: PT Pradnya Paramita

Yoeti, Oka.A. (1997). Perencanaan dan Pengembangan Pariwisata. Jakarta: PT Pradnya Paramita 